\title{
Avaliação de Desempenho, Rendimento de Carcaça e Qualidade da Carne do Peito em Frangos de Linhagens de Conformação versus Convencionais ${ }^{1}$
}

\author{
Joerley Moreira ${ }^{2}$, Ariel Antônio Mendes ${ }^{3}$, Edivaldo Antônio Garcia ${ }^{3}$, Ricardo Pinto de Oliveira², \\ Rodrigo Garófallo Garcia ${ }^{2}$, Ibiara Correia Lima de Almeida ${ }^{4}$
}

\begin{abstract}
RESUMO - O trabalho foi conduzido com o objetivo de avaliar o efeito de diferentes linhagens (conformação versus convencionais) sobre o desempenho, rendimento de carcaça e partes, medidas físicas (espessura, largura e comprimento do filé do peito) e qualidade da carne do peito (perda de peso por cozimento, maciez e pH) em frangos de corte com 35, 42 e 49 dias. Foram utilizados 2400 pintos de um dia, distribuídos em um delineamento inteiramente casualizado em fatorial 5x2, com cinco linhagens (conformação A, B e C ; e convencionais D e E) e dois sexos, com quatro repetições de 60 aves cada. O crescimento das aves foi diferente, havendo linhagens com maior crescimento tanto entre as de conformação quanto entre as convencionais. As linhagens apresentaram desempenho diferenciado para ganho de peso, consumo de ração e conversão alimentar. Os animais de algumas linhagens de conformação apresentaram desempenho superior às convencionais, mas o oposto também foi verificado. O rendimento de carcaça diferiu aos 35 dias, com as linhagens de conformação apresentando os maiores rendimentos. O rendimento de pernas e carne de pernas foi semelhante ou melhor nas linhagens convencionais e os maiores rendimentos de peito e carne de peito ocorreram nas linhagens de conformação. A gordura abdominal diferiu aos 42 dias somente entre as linhagens de conformação. A espessura, largura e comprimento dos filés do peito também foram diferentes, com as linhagens de conformação apresentando valores semelhantes entre si e superiores aos das linhagens convencionais. Não houve diferenças nos parâmetros de qualidade da carne. O sexo das aves teve influência tanto no desempenho quanto no rendimento de carcaça e partes, porém não afetou a qualidade da carne do peito.
\end{abstract}

Palavras-chave: desempenho, frangos de corte, linhagens, qualidade da carne, rendimento de carcaça

\section{Evaluation of Performance, Carcass Yield and Breast Meat Quality in Broilers of Conformation versus Conventional Strain}

\begin{abstract}
The objective of this work was to evaluate the effect of different commercial strain (conformation versus conventional) on performance, carcass yield and parts, physical determinations (thickness, width and length of breast fillet) and breast meat quality (weight loss for cooking, shear force and $\mathrm{pH}$ ) in broilers with 35, 42 and 49 days of age. Two thousand and four hundred day-old chicks were assigned to a randomized $5 \times 2$ factorial design, with five strains (conformation: A, B and C; and conventional D and E) and two sex, with four replicates of 60 birds each. The birds growth rate was different. Some strains showed higher growth rate among the conformation strains, as well as among the conventional ones. Strains also showed different performance for weight gain, feed intake and feed:gain ratio. Among the conformation strains, there was a strain that showed higher performance than the conventional ones, but the opposite was also verified. Carcass yield was affected at 35 days, and conformation strains presented the highest yield. Leg and leg meat yield were similar or better in the conventional strain, even so the highest breast and breast meat yield was observed for the conformation strain. Abdominal fat differed to 42 days but, only among onformation strain. Thickness, width and length of breast fillet were also different, and the conformation strain showed similar values to each other and superior than the conventional strain. There were no differences for meat quality. Sex of the birds affected the performance and carcass yield and parts, but did not affect the breast meat quality.
\end{abstract}

Key Words: broilers, carcass yield, performance, quality meat, strain

\section{Introdução}

No passado, o mercado mundial era dominado por linhagens clássicas (convencionais), que apresentavam bons resultados de ganho de peso e conversão alimentar, sendo dada pouca importância à conformação do frango. Atualmente, as linhagens clássicas estão desaparecendo rapidamente e perdendo importância a cada dia. A pressão de seleção cada vez maior para alto rendimento de carcaça e partes faz

\footnotetext{
${ }_{1}^{1}$ Parte da tese de Doutorado do primeiro autor.

2 Zootecnista, doutorando em Zootecnia pelo DPEA da FMVZ-UNESP, Campus de Botucatu - SP. E.mail: joerley@fca.unesp.br

${ }^{3}$ Professores do DPEA da FMVZ-UNESP, Campus de Botucatu - SP.

${ }^{4}$ Zootecnista, mestranda em Zootecnia pelo DPEA da FMVZ-UNESP, Campus de Botucatu - SP.
} 
com que a indústria tenha a sua disposição aves cada vez mais específicas. Com isso, a indústria de processamento tende a valorizar um peito mais longo e mais uniforme em espessura muscular, para adaptar-se às novas exigências dos processos culinários, o que se deve ao melhor aproveitamento nos cortes específicos, diminuindo sobras e retalhos. Outro benefício é o cozimento e/ou fritura uniforme dos filés utilizados por empresas produtoras de alimentos semi-prontos (Bakker, 1999).

Atualmente, a produção de frangos de corte adotou critérios importantes, como rendimento de carcaça, produção de carne de peito e de pernas e qualidade da carcaça e da carne. A importância dessas características varia de acordo com a empresa, o tipo de produto comercializado e o mercado ao qual o produto se destina.

Embora praticamente todas as linhagens existentes hoje no mercado sejam de alto rendimento, existem diferenças entre as mesmas, pois o resultado final depende da pressão de seleção aplicada no programa de formação da linhagem. Assim, o rendimento de carcaça e das partes varia dentro de uma mesma linhagem, conforme a idade e o peso de abate. Dessa forma, uma avaliação correta do rendimento é fundamental, a fim de evitar tomadas de decisão equivocadas, o que certamente afetará a rentabilidade da empresa (Mendes, 2001).

Segundo Castillo (2001), a qualidade da carcaça e da carne de frangos é cada vez mais exigida, devido a uma série de mudanças no hábito de consumo, como cortes e produtos desossados de carne que estão sendo mais procurados para o processamento, crescimento do consumo de produtos de preparo rápido, bem como maior participação da mulher no mercado de trabalho.

Assim, com a comercialização de cortes e de produtos desossados, muitos dos defeitos na carne se tornaram aparentes ocasionando a rejeição dos mesmos. Da mesma forma, as características sensoriais de cada corte, como aparência e maciez puderam ser melhor percebidas e reconhecidas pelo consumidor (Beraquet, 1999).

O presente trabalho foi conduzido com o objetivo de avaliar desempenho, rendimento de carcaça e partes, parâmetros físicos e características da qualidade da carne do peito de frangos de corte de diferentes linhagens comerciais convencionais e de conformação em diferentes idades de abate.

\section{Material e Métodos}

Foi realizado um experimento, com duração de 49 dias, conduzido nas instalações experimentais da Faculdade de Medicina Veterinária e Zootecnia da UNESP, Campus de Botucatu, no período de fevereiro a abril de 2002. Foram utilizados 2400 pintos de um dia de idade, sexados, provenientes de ovos incubados em uma mesma máquina do incubatório Salas Pinheiro, localizado em Guareí - SP. O delineamento experimental adotado foi o inteiramente casualisado em fatorial $5 \times 2$, com cinco linhagens, sendo três de conformação (Ross 308, Cobb 500 e Hubbard) e duas convencionais (MPK e Vedete) e dois sexos, com quatro repetições de 60 aves cada. A idade das matrizes (semanas) e o peso médio dos ovos (g) foram, respectivamente: Ross 308, 37 e 66,6; Cobb 500, 43 e 66,9; Hubbard, 41 e 63,4; MPK, 40 e 65,7; e Vedete, 40 e 60,6.

As aves foram alojadas em um galpão experimental contendo 48 boxes de $3,25 \times 1,55 \mathrm{~m}$, perfazendo $5 \mathrm{~m}^{2}$ cada. Cada boxe foi equipado com uma campânula, um comedouro tubular e um bebedouro pendular.

Adotou-se um programa de alimentação com ração farelada em quatro fases: pré-inicial (1 a 7 dias), inicial (8 a 21 dias), crescimento (22 a 42 dias) e final (43 a 49 dias). As dietas foram formuladas de acordo com as recomendações de Rostagno et al. (2000) e estão apresentadas na Tabela 1. Água e ração foram fornecidas à vontade. As temperaturas máxima, mínima e média registradas diariamente às 9 e $15 \mathrm{~h}$ foram 31,$0 ; 21,9$ e $26,5^{\circ} \mathrm{C}$, respectivamente.

Foram avaliados os seguintes parâmetros de desempenho: peso médio inicial (um dia de idade), ganho de peso, consumo de ração e conversão alimentar aos 35, 42 e 49 dias. Também aos 35, 42 e 49 dias de idade, foram retiradas amostras de cinco aves por boxe, perfazendo um total de 20 aves por tratamento e 200 aves no total para avaliação do rendimento de carcaça e partes, determinações físicas e parâmetros de qualidade da carne do peito. Os parâmetros de rendimento avaliados foram: rendimento de carcaça, pernas, carne de pernas, peito, carne de peito e percentagem de gordura abdominal. Para o cálculo do rendimento de carcaça e gordura abdominal, foi tomado como base o peso vivo obtido individualmente na plataforma e para as demais partes, o peso da carcaça eviscerada (sem cabeça, pescoço 
Tabela 1 - Composição percentual das rações experimentais

Table 1 - Composition of the experimental diets

\begin{tabular}{|c|c|c|c|c|}
\hline \multirow{3}{*}{$\begin{array}{l}\text { Ingredientes (\%) } \\
\text { Ingredients (\%) }\end{array}$} & \multicolumn{4}{|c|}{$\begin{array}{l}\text { Rações experimentais } \\
\text { Experimental diets }\end{array}$} \\
\hline & Pré-Inicial & Inicial & Crescimento & Final \\
\hline & Pre-Starter & Starter & Grower & Finishing \\
\hline Milho (Corn) & 56,627 & 59,309 & 62,746 & 65,076 \\
\hline Farelo de soja (Soybean meal) & 37,096 & 34,349 & 30,304 & 27,146 \\
\hline Óleo de soja (Soybean oil) & 2,051 & 2,328 & 3,231 & 4,298 \\
\hline Fosfato Bicálcico (Dicalcium phosphate) & 1,892 & 1,774 & 1,612 & 1,411 \\
\hline Calcário (Limestone) & 0,997 & 0,967 & 0,934 & 0,895 \\
\hline DL-Metionina (DL-Methionine) & 0,250 & 0,227 & 0,212 & 0,160 \\
\hline L-Lisina (L-Lysine) & 0,237 & 0,196 & 0,211 & 0,164 \\
\hline \multicolumn{5}{|l|}{ Suplemento mineral e vitamínico ${ }^{1}$} \\
\hline Mineral and vitamin supplement & 0,500 & 0,500 & 0,400 & 0,500 \\
\hline Sal (Salt) & 0,350 & 0,350 & 0,350 & 0,350 \\
\hline \multicolumn{5}{|l|}{ Composição calculada (Calculated composition), \% } \\
\hline $\mathrm{EM}(\mathrm{kcal} / \mathrm{kg})(E M, \mathrm{kcal} / \mathrm{kg})$ & 2950 & 3000 & 3100 & 3200 \\
\hline Proteína bruta (Crude protein) & 21,915 & 20,877 & 19,300 & 18,000 \\
\hline Cálcio (Calcium) & 0,988 & 0,939 & 0,874 & 0,800 \\
\hline Fósforo disponível (Available phosphorus) & 0,466 & 0,441 & 0,406 & 0,365 \\
\hline Metionina (Methionine) & 0,507 & 0,483 & 0,453 & 0,410 \\
\hline Met + Cis $($ Met + Cys $)$ & 0,926 & 0,879 & 0,825 & 0,742 \\
\hline Lisina (Lysine) & 1,350 & 1,25 & 1,156 & 1,040 \\
\hline
\end{tabular}

${ }^{1}$ Suplemento Mineral e Vitamínico Puramix (Purina).

e pés). Foi considerada como gordura abdominal, a gordura presente na região da cloaca e aquela aderida a moela. Para as determinações do comprimento, largura e espessura do peito, foi utilizado o músculo Pectoralis major. Estas medidas foram feitas com o auxílio de um paquímetro e de uma régua comum, sendo a altura medida na parte mais espessa do músculo. Para determinação da perda de peso por cozimento, foram utilizados os filés inteiros, que após pesados degelados, foram embalados em papel alumínio e cozidos em uma chapa de duplo aquecimento uniforme até atingir a temperatura interna de $82^{\circ} \mathrm{C} \pm$ $2^{\circ} \mathrm{C}$. A seguir, as amostras foram colocadas sobre papel absorvente para resfriamento até atingir a temperatura de 20 a $25^{\circ} \mathrm{C}$. Novamente as amostras foram pesadas e determinadas a perda de peso após o cozimento. Estas amostras foram envolvidas com papel absorvente para remoção da umidade superficial, embaladas em sacos plásticos e mantidas sob refrigeração a $4^{\circ} \mathrm{C}$ por 24 horas para determinação da maciez (Honikel, 1987). Para determinação da força de cisalhamento (maciez) foram utilizadas todas as amostras usadas na determinação da perda de peso por cozimento. Foram retiradas amostras na forma de paralelepípedos com $2 \times 2 \times 1,13 \mathrm{~cm}$, as quais foram colocadas com as fibras orientadas no sentido perpendicular às lâminas do aparelho Warner-Bratzler, acoplado ao aparelho Instron M 2318, conforme técnica descrita por Froning et al. (1978). Realizou-se também determinação do $\mathrm{pH}$ dos filés, feita através de eletrodo de penetração, diretamente no peito das aves, quando da análise de qualidade da carne.

A análise estatística dos resultados foram processadas utilizando-se o procedimento GLM do SAS. Foi realizada também uma análise de correlação feita no EXCEL (1998), correlacionando o peso dos filés do peito com os dados de espessura, largura e comprimento, nas diferentes idades de abate.

\section{Resultados e Discussão}

\section{Crescimento das linhagens}

Os dados referentes ao crescimento semanal das linhagens estão apresentados na Tabela 2. Embora tenha se tomado o cuidado de homogeneizar as idades das matrizes e o peso dos ovos, houve diferenças no peso inicial dos pintinhos com um dia de idade tanto entre as linhagens de conformação quanto entre as linhagens convencionais. No entanto, o peso do pintinho não refletiu em maior peso vivo aos 35, 42 e 49 dias, pois as linhagens que apresentaram os menores pesos iniciais foram as que tiveram o maior peso vivo, o que permite mostrar que, quando os pintinhos são de 
Tabela 2 - Crescimento de frangos de corte de linhagens de conformação versus convencional, em g/ave Table 2 - Growth of broilers of conformation strain versus conventional strain, g/bird

\begin{tabular}{|c|c|c|c|c|c|c|}
\hline \multirow[t]{2}{*}{$\begin{array}{l}\text { Idade (dias) } \\
\text { Age days }\end{array}$} & \multirow[t]{2}{*}{$\begin{array}{l}\text { Sexo } \\
\text { Sex }\end{array}$} & \multicolumn{3}{|c|}{$\begin{array}{l}\text { Conformação } \\
\text { Conformation }\end{array}$} & \multicolumn{2}{|c|}{$\begin{array}{c}\text { Convencionais } \\
\text { Conventional }\end{array}$} \\
\hline & & $\mathrm{A}$ & $\mathrm{B}$ & $\mathrm{C}$ & $\mathrm{D}$ & $\mathrm{E}$ \\
\hline \multirow[t]{3}{*}{1} & Macho (Male) & 45,5 & 47,3 & 45,0 & 46,9 & 41,8 \\
\hline & Fêmea (Female) & 44,9 & 46,7 & 45,1 & 46,5 & 40,9 \\
\hline & Média (Mean) & $45,2^{\mathrm{b}}$ & $47,0^{\mathrm{a}}$ & $45,0^{\mathrm{b}}$ & $46,7^{\mathrm{a}}$ & $41,3^{\mathrm{c}}$ \\
\hline \multirow[t]{3}{*}{7} & Macho (Male) & 186 & 178 & 180 & 176 & 181 \\
\hline & Fêmea (Female) & 183 & 168 & 172 & 171 & 181 \\
\hline & Média (Mean) & $184^{\mathrm{a}}$ & $173^{c}$ & $176^{b c}$ & $173^{c}$ & $181^{\mathrm{a}}$ \\
\hline \multirow[t]{3}{*}{14} & Macho (Male) & 451 & 431 & 452 & 423 & 458 \\
\hline & Fêmea (Female) & 435 & 396 & 418 & 396 & 435 \\
\hline & Média (Mean) & $443^{\mathrm{a}}$ & $413^{b}$ & $435^{\mathrm{a}}$ & $409^{b}$ & 447 \\
\hline \multirow[t]{3}{*}{21} & Macho (Male) & 850 & 831 & 844 & 806 & 877 \\
\hline & Fêmea (Female) & 788 & 740 & 778 & 717 & 798 \\
\hline & Média (Mean) & $819^{a b}$ & $786^{\mathrm{c}}$ & $811^{\mathrm{b}}$ & $761^{d}$ & $837^{\mathrm{a}}$ \\
\hline \multirow[t]{3}{*}{28} & Macho (Male) & 1436 & 1370 & 1454 & 1337 & 1475 \\
\hline & Fêmea (Female) & 1257 & 1191 & 1248 & 1149 & 1287 \\
\hline & Média (Mean) & $1347^{b}$ & $1281^{\mathrm{c}}$ & $1351^{\mathrm{ab}}$ & $1243^{\mathrm{d}}$ & $1381^{\mathrm{a}}$ \\
\hline \multirow[t]{3}{*}{35} & Macho (Male) & 2061 & 1963 & 2096 & 1935 & 2095 \\
\hline & Fêmea (Female) & 1769 & 1679 & 1748 & 1623 & 1788 \\
\hline & Média (Mean) & $1915^{\mathrm{a}}$ & $1821_{b}$ & $1922^{\mathrm{a}}$ & $1784^{\mathrm{b}}$ & $1941^{\mathrm{a}}$ \\
\hline \multirow[t]{3}{*}{42} & Macho (Male) & 2630 & $2487^{\circ}$ & 2710 & 2487 & 2608 \\
\hline & Fêmea (Female) & 2236 & 2134 & 2219 & 2070 & 2248 \\
\hline & Média (Mean) & $2433^{\mathrm{a}}$ & $2311^{b}$ & $2464^{\mathrm{a}}$ & $2278^{b}$ & $2425^{a}$ \\
\hline \multirow[t]{3}{*}{49} & Macho (Male) & 3236 & 3037 & 3295 & 3077 & 3208 \\
\hline & Fêmea (Female) & 2741 & 2618 & 2731 & 2569 & 2725 \\
\hline & Média (Mean) & $2989^{a}$ & $2827^{\mathrm{b}}$ & $3013 \mathrm{a}$ & $2823^{\mathrm{b}}$ & $2967^{\mathrm{a}}$ \\
\hline
\end{tabular}

Médias seguidas de letras diferentes nas linhas, diferem $(p<0,05)$ entre si pelo teste Tukey.

Means followed by letters differents in a row, differ $(p<.05)$ by Tukey test.

linhagens diferentes, o maior peso inicial pode não resultar em maior peso vivo final. Tanto entre as linhagens de conformação quanto entre as linhagens convencionais, houve algumas com melhor crescimento e outras com crescimento comparável entre si, observando-se que, nas idades avaliadas, duas das três linhagens de conformação apresentaram peso vivo semelhante a uma das linhagens convencionais testadas.

Ganho de peso, consumo de ração e conversão alimentar

Os parâmetros de desempenho, rendimento de carcaça e partes estão apresentados nas Tabelas 3, 4, 5 e 6.

Os ganhos de peso aos 35, 42 e 49 dias apresentam comportamento semelhante, sendo que ocorreu resultados melhores e piores tanto entre as linhagens de conformação quanto entre as convencionais. Houve linhagens de conformação que apresentaram melhor ganho de peso que as convencionais, mas também foi verificada superioridade de linhagens convencionais em relação à linhagens de conformação. Constata-se que, para esta característica, há linhagens com maior eficiência tanto entre as de conformação quanto entre as convencionais.

O consumo de ração aos 35 dias foi maior para as aves que apresentaram o maior ganho de peso, ocorrendo diferenças tanto entre as linhagens de conformação quanto entre as convencionais. Aos 42 dias, já foi possível destacar que os animais de algumas linhagens de conformação, apesar de apresentarem o mesmo ganho de peso, mostraram consumo de ração superior, o que se evidencia mais ainda aos 49 dias. Entre as linhagens convencionais, houve diferenças apenas aos 42 dias, mas aos 49 dias o consumo foi semelhante, apesar de o ganho de peso ter sido diferenciado. Isto mostra que há maior especificidade entre as linhagens e linhagens que apresentam o mesmo ganho de peso que outras, porém com menor consumo de ração, o que reflete diretamente sobre os custos de produção. Esta especificidade foi maior, à medida que aumentou a idade das aves. Os machos apresentaram maior consumo de ração do que as fêmeas. 
Tabela 5 - Parâmetros de desempenho e rendimento de carcaça de frangos de corte de linhagens de conformação versus convencionais aos 49 dias de idade

Table 5 - Parameters of performance and carcass yield of broilers of conformation strain versus conventional strain at 49 days of age

\begin{tabular}{|c|c|c|c|c|c|c|c|c|c|}
\hline $\begin{array}{l}\text { Parâmetros } \\
\text { Parameters }\end{array}$ & $\begin{array}{l}\text { Ganho de } \\
\text { peso, g } \\
\text { Weight } \\
\text { gain, } g\end{array}$ & $\begin{array}{l}\text { Consumo de } \\
\text { ração, g } \\
\text { Feed } \\
\text { intake, } g\end{array}$ & $\begin{array}{l}\text { Conversão } \\
\text { alimentar } \\
\text { Feed } \\
\text { conversion }\end{array}$ & $\begin{array}{c}\text { Carcaça, } \\
\% 1 \\
\text { Carcass, } \\
\%\end{array}$ & $\begin{array}{c}\text { Pernas, } \\
\% \\
\text { Legs, } \\
\%\end{array}$ & $\begin{array}{l}\text { Carne de } \\
\text { pernas, } \% \\
\text { Legs } \\
\text { meat, \% }\end{array}$ & $\begin{array}{l}\text { Peito, } \\
\% \\
\text { Breast, } \\
\%\end{array}$ & $\begin{array}{c}\text { Carne de } \\
\text { peito, } \% \\
\text { Breast } \\
\text { meat, } \%\end{array}$ & $\begin{array}{c}\text { Gordura } \\
\text { abdominal } \\
\text { Abdominal } \\
\text { fat }\end{array}$ \\
\hline \multicolumn{10}{|l|}{ Conformação } \\
\hline \multicolumn{10}{|l|}{ Conformation } \\
\hline A & $2989^{a}$ & $5439^{b}$ & $1,82^{\mathrm{a}}$ & 71,42 & 33,10 & 22,01 & $34,70^{\mathrm{b}}$ & $25,88^{\mathrm{b}}$ & 2,50 \\
\hline B & $2827^{b}$ & $5215^{b}$ & $1,85^{\mathrm{ab}}$ & 70,53 & 33,59 & 22,32 & $34,73^{b}$ & $25,68^{b}$ & 2,20 \\
\hline $\mathrm{C}$ & $3013^{a}$ & $5689^{a}$ & $1,89^{b}$ & 71,57 & 31,71 & 21,91 & $36,84^{\mathrm{a}}$ & $27,86^{\mathrm{a}}$ & 2,52 \\
\hline \multicolumn{10}{|c|}{ Convencionais } \\
\hline $\begin{array}{l}\text { Conventional } \\
\text { D }\end{array}$ & $2823^{b}$ & $5269^{b}$ & $1,87^{\mathrm{ab}}$ & 70,61 & 33,33 & 22,02 & $34,43^{b}$ & $25,78^{\mathrm{b}}$ & 2,55 \\
\hline $\mathrm{E}$ & $2967^{\mathrm{a}}$ & $5448^{a b}$ & $1,84^{\mathrm{a}}$ & 70,90 & 33,53 & 22,03 & $34,00^{\mathrm{b}}$ & $25,07^{\mathrm{b}}$ & 2,35 \\
\hline \multicolumn{9}{|l|}{ Sexo } & \\
\hline $\begin{array}{l}\text { Macho } \\
\text { Male }\end{array}$ & $3170^{\mathrm{a}}$ & $5755^{\mathrm{a}}$ & $1,81^{\mathrm{a}}$ & 71,07 & 33,78 & 22,39 & $34,33^{b}$ & $25,68^{\mathrm{b}}$ & $2,06^{\mathrm{b}}$ \\
\hline $\begin{array}{l}\text { Fêmea } \\
\text { Female }\end{array}$ & $2677^{b}$ & $5070^{\mathrm{b}}$ & $1,89^{\mathrm{b}}$ & 70,95 & 32,33 & 21,37 & $35,55^{\mathrm{a}}$ & $26,43^{\mathrm{a}}$ & $2,79^{\mathrm{a}}$ \\
\hline CV $(\%)$ & 2,36 & 3,15 & 1,76 & 1,29 & 1,83 & 3,01 & 1,95 & 2,64 & 13,56 \\
\hline
\end{tabular}

Médias seguidas de letras minúsculas diferentes nas colunas, dentro de cada fator, diferem entre si pelo teste de Tukey $(p<0,05)(M e a n s$ followed by different small letters in a collumn, for each factor, differ [ $p<.05]$ by Tukey test).

${ }^{1}$ Carcaça eviscerada sem cabeça, pescoço, patas e gordura abdominal (Eviscerated carcass without head, neck, foot and abdominal fat).

A conversão alimentar mostrou-se como um fator bastante específico entre as linhagens. Para as linhagens convencionais, houve diferenças apenas aos 35 dias, já entre as linhagens de conformação, estas diferenças ocorreram nas três idades avaliadas, denotando maior especificidade de conversão de ração em carne entre as linhagens de conformação. A linhagem de conformação que apresentou os maiores ganhos de peso e consumo de ração foi a que apresentou os piores valores de conversão alimentar, o que reforça a necessidade de realizar uma análise econômica para se escolher a linhagem a produzir, uma vez que existem linhagens com alto rendimento, porém, com elevado custo de produção, devido ao alto consumo de ração e conversão alimentar ruim. Os machos apresentaram melhor conversão alimentar do que as fêmeas.

Nas três idades avaliadas neste trabalho $(35,42 \mathrm{e}$ 49 dias), houve diferenças no ganho de peso, consumo de ração e conversão alimentar entre as linhagens testadas. Relata-se, na literatura, que essas diferenças são devidas a diferenças de material genético resultante da seleção adotada pelas empresas de melhoramento. Os resultados obtidos para o desempenho assemelham-se aos verificados com diferentes linhagens comerciais disponíveis no mercado brasileiro na última década (Soares et al., 1991; Mendes et al., 1993; Mizubuti et al., 1994; Abreu et al., 1996; Vieira
\& Moran, 1998; Lisboa et al., 1999b; Araújo et al., 1999; Farran et al., 2000; Fernandes et al., 2001).

\section{Rendimento de carcaça}

Os rendimentos de carcaça e partes estão apresentados nas Tabelas 3, 4 e 5. Para o abate aos 35 dias, não houve diferenças significativas $(\mathrm{p}>0,05)$ entre as linhagens convencionais e nem entre as de conformação, mas houve linhagens de conformação que superaram as convencionais, porém, o oposto não foi observado, mostrando que, nesta idade, mesmo as linhagens de conformação de menor rendimento de carcaça se equivalem as linhagens convencionais. Quando as aves foram abatidas tanto aos 42 como aos 49 dias de idade, não houve diferenças significativas ( $p>0,05)$ sobre o rendimento de carcaça, apesar de aos 42 dias os rendimentos das linhagens de conformação apresentarem valores numéricos maiores do que os rendimentos apresentados pelas linhagens convencionais. Não houve diferenças no rendimento de carcaça entre machos e fêmeas. Apesar de os dados não constarem nas tabelas apresentadas, verificou-se que as diferenças entre os rendimentos de carcaça para machos e fêmeas foram maiores nas linhagens convencionais, porém, nas linhagens de conformação, estas diferenças não ocorreram, o que provavelmente fez com que os dados não diferissem entre si. 


\section{Rendimento de pernas e carne de pernas}

Houve interações significativas $(\mathrm{p}<0,05)$ para $\mathrm{o}$ rendimento de carne de pernas aos 35 dias e para o rendimento de pernas e carne de pernas aos 49 dias, como mostrado na Tabela 6. Quando o abate das aves foi realizado aos 35 dias, o rendimento de pernas foi maior nas linhagens convencionais. Com relação ao rendimento de carne de pernas, verificou-se que as linhagens convencionais apresentaram resultados semelhantes a algumas linhagens de conformação e superiores a outras, sem no entanto apresentar valores inferiores. É interessante destacar que apenas entre as linhagens de conformação houve diferenças entre machos e fêmeas, com os machos apresentando os maiores rendimentos. Para o abate aos 42 dias, não houve diferença entre as linhagens, mas nesta idade, o rendimento dos machos foi superior aos das fêmeas. Quando as aves foram abatidas com 49 dias, os resultados confirmaram os obtidos nas idades anteriores, porém, houve diferença para carne de pernas apenas entre as fêmeas. Os dados também acusaram diferenças entre machos e fêmeas apenas entre as linhagens de conformação.

Rendimento de peito e carne de peito

O comportamento para o rendimento de peito e carne de peito foi semelhante nas três idades avalia- das, com as linhagens de conformação apresentando valores semelhantes ou superiores aos das linhagens convencionais. Os resultados mostram que houve diferenças entre as linhagens de conformação e, entre estas, há linhagens que são superiores às convencionais para o rendimento tanto de peito quanto de carne de peito, porém, é conveniente salientar que também há linhagens convencionais com rendimentos semelhantes em relação a algumas linhagens de conformação. É interessante perceber que as linhagens de conformação representam avanço genético para esta característica, uma vez que nenhuma das linhagens testadas apresentaram valores inferiores aos das linhagens convencionais para o abate com 35 , 42 e 49 dias de idade. O sexo das aves teve influência significativa $(\mathrm{p}<0,05)$ para o rendimento de peito e a carne de peito, com as fêmeas apresentando os melhores resultados.

\section{Gordura abdominal}

Houve diferenças $(\mathrm{p}<0,05)$ nas porcentagens de gordura abdominal apenas com 42 dias, sendo que tanto a maior quanto a menor porcentagem aconteceu entre as linhagens de conformação. O sexo das aves teve efeito significativo $(\mathrm{p}<0,05)$ sobre este parâmetro, sendo que as fêmeas apresentaram as maiores porcentagens.

Tabela 6 - Desdobramento da interação entre linhagem x sexo para rendimento de carne de pernas aos 35 e 49 dias e rendimento de pernas aos 49 dias

Table 6 - Decomposition of the interaction strain $x$ sex for leg meat yield at 35 and 49 days and leg yield at 49 days of age

\begin{tabular}{|c|c|c|c|c|c|c|c|}
\hline \multirow[t]{2}{*}{$\begin{array}{l}\text { Parâmetros } \\
\text { Parameters }\end{array}$} & \multirow[t]{2}{*}{$\begin{array}{l}\text { Sexo } \\
\text { Sex }\end{array}$} & \multicolumn{3}{|c|}{$\begin{array}{l}\text { Conformação } \\
\text { Conformation }\end{array}$} & \multicolumn{2}{|c|}{$\begin{array}{c}\text { Convencionais } \\
\text { Conventional }\end{array}$} & \multirow[t]{2}{*}{$\begin{array}{l}\text { Médias } \\
\text { Means }\end{array}$} \\
\hline & & $\mathrm{A}$ & B & $\mathrm{C}$ & $\mathrm{D}$ & $\mathrm{E}$ & \\
\hline $\begin{array}{l}\text { Carne de pernas, } \% \\
\text { Leg meat, } \%\end{array}$ & $\begin{array}{l}\text { Macho } \\
\text { Fêmea } \\
\text { Média }\end{array}$ & $\begin{array}{l}\text { Ren } \\
21,80^{\mathrm{ab}} \\
19,91^{\mathrm{b}} \\
20,85\end{array}$ & $\begin{array}{l}\text { nto aos } 3 \\
\text { at } 35 \text { day } \\
22,97^{\mathrm{Aa}} \\
21,31^{\mathrm{Ba}} \\
22,14\end{array}$ & $\begin{array}{l}21,01^{b} \\
19,85^{b} \\
20,43\end{array}$ & $\begin{array}{l}22,18^{\mathrm{ab}} \\
21,22^{\mathrm{ab}} \\
21,70\end{array}$ & $\begin{array}{l}21,71^{\mathrm{ab}} \\
21,78^{\mathrm{a}} \\
21,75\end{array}$ & $\begin{array}{l}21,93 \\
20,81\end{array}$ \\
\hline $\begin{array}{l}\text { Pernas, \% } \\
\text { Legs, \% }\end{array}$ & $\begin{array}{l}\text { Macho } \\
\text { Fêmea } \\
\text { Média }\end{array}$ & $\begin{array}{l}\text { Ren } \\
34,00^{\mathrm{Aab}} \\
32,20^{\mathrm{Ba}} \\
33,10\end{array}$ & $\begin{array}{l}\text { nto aos } 4 \\
\text { at } 49 \text { day } \\
34,44^{\mathrm{Aa}} \\
32,74 \mathrm{Ba} \\
33,59\end{array}$ & $\begin{array}{l}32,86^{\mathrm{ab}} \\
30,57^{\mathrm{Bb}} \\
31,71\end{array}$ & $\begin{array}{l}33,89^{\mathrm{ab}} \\
32,76^{\mathrm{a}} \\
33,33\end{array}$ & $\begin{array}{l}33,71^{\mathrm{ab}} \\
33,35^{\mathrm{a}} \\
33,53\end{array}$ & $\begin{array}{l}33,78 \\
32,33\end{array}$ \\
\hline $\begin{array}{l}\text { Carne de pernas, } \% \\
\text { Leg meat, } \%\end{array}$ & $\begin{array}{l}\text { Macho } \\
\text { Fêmea } \\
\text { Média }\end{array}$ & $\begin{array}{l}\text { Ren } \\
22,84^{\mathrm{A}} \\
21,17^{\mathrm{Bab}} \\
22,01\end{array}$ & $\begin{array}{l}\text { nto aos } 4 \\
\begin{array}{l}\text { at } 49 \text { da } \\
23,05 \\
21,60^{\text {ab }} \\
22,32\end{array}\end{array}$ & $\begin{array}{l}21,92^{\mathrm{A}} \\
20,11^{\mathrm{Bb}} \\
21,01\end{array}$ & $\begin{array}{l}22,33 \\
21,71^{a} \\
22,02\end{array}$ & $\begin{array}{l}21,82 \\
22,25^{a} \\
22,03\end{array}$ & $\begin{array}{l}22,39 \\
21,37\end{array}$ \\
\hline
\end{tabular}

Médias seguidas de letras diferentes, minúsculas nas linhas e maiúsculas nas colunas, diferem entre si pelo teste de Tukey $(p<0,05)$. Means followed by different letters, small in row and capital in column, differ $(p<.05)$ by Tukey test. 
Comprimento, largura e espessura do filé do peito

Os valores médios do comprimento, largura e espessura dos filé de peito estão apresentados na Tabela 7. Os resultados de correlação entre o peso dos filés e espessura, largura e comprimento foram de $0,81,0,63$ e 0,71 respectivamente. As linhagens apresentaram diferenças $(\mathrm{p}<0,05)$ para estas variáveis nas três idades de abate avaliadas. Percebe-se que, para a espessura do filé, houve diferenças $(p<0,05)$ aos 42 dias, somente entre as linhagens de conformação. Assim, os valores de espessura dos filés de peito nas linhagens de conformação foram semelhantes ou superiores aos das linhagens convencionais. Valores médios de espessura, largura e comprimento $(\mathrm{cm})$ dos filés do peito de frangos de linhagens de conformação versus convencionais aos 35,42 e 49 dias de idade foram diferentes entre as linhagens com 35 e 49 dias, apresentando resultados semelhantes aos da espessura do peito, ou seja, as linhagens de conformação tiveram largura do filé do peito semelhante ou superior aos das linhagens convencionais, porém, neste parâmetro, não houve diferenças entre as linhagens de conformação, e nem entre as linhagens convencionais. Os comprimentos dos filés do peito também diferiram entre si $(\mathrm{p}<0,05)$ nas três idades avaliadas, sendo notadas diferenças tanto entre as linhagens de conformação quanto entre as linhagens convencionais mas, novamente, as linhagens de conformação apresentaram valores semelhantes ou superiores às linhagens convencionais. $\mathrm{O}$ sexo das aves teve influência em todos os parâmetros, sendo que os machos apresentaram resultados superiores aos das fêmeas em todos eles.
Lubritz (1997) encontrou efeito da linhagem e do sexo sobre o comprimento, espessura e peso do peito, sendo que as linhas selecionadas com maior ênfase em conformação e rendimento apresentaram filés mais curtos, espessos e pesados. O autor encontrou também uma correlação positiva entre o comprimento, largura e espessura do filé com o peso do filé, total de carne branca e porcentagem de carne branca.

Rendimento e qualidade da carne do filé do peito

Os rendimentos dos filés do peito e os parâmetros de qualidade da carne estão mostrados na Tabela 8 . Verifica-se que houve diferenças significativas $(p<0,05)$ entre as linhagens e o sexo das aves apenas quanto ao rendimento do filé do peito, nas três idades de abate avaliadas, refletindo os resultados observados para o rendimento da carne do peito. Portanto, o peso dos filés confirma que, apesar de haver diferenças entre as linhagens de conformação, estas se mostram semelhantes ou superiores as convencionais para esta característica. Percebe-se também que as linhagens convencionais não diferiram entre si para o rendimento do filé do peito.

Os parâmetros de qualidade da carne avaliados não apresentaram diferenças com relação á linhagem ou sexo, mas é possível relacionar os comportamentos destes em função da idade. Observa-se que há tendência de redução da perda de peso por cozimento, com o aumento da idade de abate, e também aumento da força de cizalhamento, o que provavelmente ocorre em função do aumento do peso dos filés. Os valores de $\mathrm{pH}$ mostraram-se semelhantes e parecem não ter sofrido influência da linhagem, sexo e idade das aves.

Tabela 7 - Valores médios de espessura, largura e comprimento $(\mathrm{cm})$ dos filés do peito de frangos de linhagens de conformação versus convencionais aos 35, 42 e 49 dias de idade

Table 7 - Average values of thickness, width and length of breast fillets of broilers of conformation strain versus conventional strain at 35, 42 and 49 days of age

\begin{tabular}{|c|c|c|c|c|c|c|c|c|c|}
\hline \multirow[t]{2}{*}{$\begin{array}{l}\text { Parâmetros } \\
\text { Parameters }\end{array}$} & \multirow[t]{2}{*}{$\begin{array}{l}\text { Idade (dias) } \\
\text { Age (days) }\end{array}$} & \multicolumn{3}{|c|}{$\begin{array}{l}\text { Conformação } \\
\text { Conformation }\end{array}$} & \multicolumn{2}{|c|}{$\begin{array}{c}\text { Convencionais } \\
\text { Conventional }\end{array}$} & \multicolumn{2}{|c|}{$\begin{array}{c}\text { Sexo } \\
\text { Sex }\end{array}$} & \multirow[t]{2}{*}{$\begin{array}{l}\mathrm{CV} \\
(\%)\end{array}$} \\
\hline & & A & B & $\mathrm{C}$ & $\mathrm{D}$ & $\mathrm{E}$ & $\begin{array}{c}\text { Macho } \\
\text { Male }\end{array}$ & $\begin{array}{l}\text { Fêmea } \\
\text { Female }\end{array}$ & \\
\hline Espessura do filé do peito & 35 & 1,9 & 1,9 & 2,0 & 1,8 & 1,8 & $1,99^{\mathrm{a}}$ & $1,81^{\mathrm{b}}$ & 7,40 \\
\hline \multirow[t]{2}{*}{ Breast fillet thickness } & 42 & $2,08^{b}$ & $2,16^{\mathrm{ab}}$ & $2,31^{\mathrm{a}}$ & $2,05^{\mathrm{b}}$ & $1,98^{\mathrm{b}}$ & $2,22^{\mathrm{a}}$ & $2,01^{\mathrm{b}}$ & 6,63 \\
\hline & 49 & 2,13 & 2,14 & 2,21 & 2,14 & 2,10 & $2,27^{\mathrm{a}}$ & $2,01^{\mathrm{b}}$ & 6,30 \\
\hline Largura do filé do peito & 35 & $6,78^{\mathrm{ab}}$ & $6,71^{\mathrm{ab}}$ & $6,97^{\mathrm{a}}$ & $6,48^{b}$ & $6,85^{\mathrm{ab}}$ & $6,87^{\mathrm{a}}$ & $6,65^{\mathrm{b}}$ & 4,47 \\
\hline \multirow[t]{2}{*}{ Breast fillet with } & 42 & 7,98 & 7,67 & 7,98 & 7,56 & 7,72 & 7,87 & 7,69 & 4,56 \\
\hline & 49 & $8,66^{\mathrm{a}}$ & $8,29^{\mathrm{ab}}$ & $8,58^{\mathrm{a}}$ & $8,20^{\mathrm{b}}$ & $8,37^{\mathrm{ab}}$ & $8,66^{\mathrm{a}}$ & $8,17^{\mathrm{b}}$ & 3,04 \\
\hline Comprimento do filé do peito & 35 & $14,30^{\mathrm{ab}}$ & $14,06^{\mathrm{ab}}$ & $14,46^{\mathrm{a}}$ & $13,82^{b}$ & $14,51^{\mathrm{a}}$ & $14,63^{\mathrm{a}}$ & $13,83^{b}$ & 2,75 \\
\hline \multirow[t]{2}{*}{ Breast fillet length } & 42 & $16,15^{\mathrm{a}}$ & $15,77^{\mathrm{ab}}$ & $16,10^{\mathrm{a}}$ & $15,27^{b}$ & $15,92^{\mathrm{ab}}$ & $16,21^{\mathrm{a}}$ & $15,48^{\mathrm{b}}$ & 3,06 \\
\hline & 49 & $17,62^{\mathrm{a}}$ & $16,98^{b c}$ & $17,31^{\mathrm{ab}}$ & $16,61^{\mathrm{c}}$ & $17,21^{\mathrm{ab}}$ & $17,71^{\mathrm{a}}$ & $16,58^{b}$ & 2,01 \\
\hline
\end{tabular}

Médias seguidas de letras diferentes, minúsculas nas linhas e maiúsculas nas colunas, diferem entre si pelo teste de Tukey $(p<0,05)$. Means followed by different letters, small in row and capital in column, differ $(p<.05)$ by Tukey test. 
Tabela 8 - Valores médios de peso do filé (g), perda de peso por cozimento (\%), força de cizalhamento (kgf/g) e pH dos filés do peito de frangos de linhagens de conformação versus convencionais aos 35, 42 e 49 dias de idade

Table 8 - Average values of fillet weight $(\mathrm{g})$, weight loss cooking (\%), shear force $(\mathrm{kgf} / \mathrm{g})$ and $\mathrm{pH}$ of breast fillets of broilers of conformation strain versus conventional strain at 35, 42 and 49 days of age

\begin{tabular}{|c|c|c|c|c|c|c|c|c|c|}
\hline \multirow[t]{2}{*}{$\begin{array}{l}\text { Parâmetros } \\
\text { Parameters }\end{array}$} & \multirow[t]{2}{*}{$\begin{array}{c}\text { Idade (dias) } \\
\text { Age (days) }\end{array}$} & \multicolumn{3}{|c|}{$\begin{array}{l}\text { Conformação } \\
\text { Conformation }\end{array}$} & \multicolumn{2}{|c|}{$\begin{array}{c}\text { Convencionais } \\
\text { Conventional }\end{array}$} & \multicolumn{2}{|c|}{$\begin{array}{l}\text { Sexo } \\
\text { Sex }\end{array}$} & \multirow[t]{2}{*}{$\begin{array}{l}\mathrm{CV} \\
(\%)\end{array}$} \\
\hline & & A & B & $\mathrm{C}$ & $\mathrm{D}$ & $\mathrm{E}$ & $\begin{array}{l}\text { Macho } \\
\text { Male }\end{array}$ & $\begin{array}{l}\text { Fêmea } \\
\text { Female }\end{array}$ & \\
\hline Peso do filé do peito & 35 & $114,5^{\mathrm{a}}$ & $106,7^{\mathrm{ab}}$ & $119,5^{\mathrm{a}}$ & $98,2^{\mathrm{b}}$ & $107,3^{\mathrm{ab}}$ & $119,6^{\mathrm{a}}$ & $98,8^{\mathrm{b}}$ & 8,28 \\
\hline \multirow[t]{2}{*}{ Breast fillet weight } & 42 & $157,0^{\mathrm{ab}}$ & $150,3^{\mathrm{b}}$ & $170,7^{\mathrm{a}}$ & $142,2^{b}$ & $144,5^{\mathrm{b}}$ & $166,5^{\mathrm{a}}$ & $139,5^{\mathrm{b}}$ & 8,52 \\
\hline & 49 & $194,2^{b}$ & $180,2^{\mathrm{b}}$ & $210,2^{\mathrm{a}}$ & $184,1^{\mathrm{b}}$ & $187,7^{\mathrm{b}}$ & $212,4^{\mathrm{a}}$ & $170,2^{\mathrm{b}}$ & 5,15 \\
\hline Perda de peso por cozimento & 35 & 26,13 & 24,64 & 26,38 & 25,64 & 24,66 & 25,44 & 25,54 & 8,10 \\
\hline \multirow[t]{2}{*}{ Weight loss cooking } & 42 & 20,76 & 21,01 & 22,62 & 21,36 & 21,24 & 21,24 & 21,55 & 8,03 \\
\hline & 49 & 17,52 & 17,60 & 18,27 & 18,57 & 16,89 & 17,60 & 17,93 & 9,70 \\
\hline Força de cizalhamento & 35 & 2,43 & 2,46 & 2,28 & 2,56 & 2,08 & 2,35 & 2,37 & 14,80 \\
\hline \multirow[t]{2}{*}{ Shear force } & 42 & 2,97 & 2,58 & 2,92 & 2,67 & 2,36 & 2,68 & 2,69 & 16,94 \\
\hline & 49 & 2,91 & 3,05 & 3,22 & 3,35 & 3,10 & 3,10 & 3,15 & 16,88 \\
\hline $\mathrm{pH}$ do filé do peito & 35 & 5,83 & 5,86 & 5,83 & 5,81 & 5,79 & 5,84 & 5,81 & 1,39 \\
\hline \multirow[t]{2}{*}{ Breast fillet $p H$} & 42 & 5,87 & 5,88 & 5,85 & 5,85 & 5,80 & 5,86 & 5,84 & 1,59 \\
\hline & 49 & 5,91 & 5,93 & 5,85 & 5,85 & 5,83 & 5,88 & 5,87 & 1,29 \\
\hline
\end{tabular}

Médias seguidas de letras diferentes nas linhas dentro de cada parâmetro e em cada idade, diferem entre si pelo teste de Tukey ( $p<0,05)$. Means followed by different letters in row, for each factor and each age, differ $(p<.05)$ by Tukey test.

Quanto aos resultados do rendimento de carcaça, partes e qualidade da carne do peito encontrados, verifica-se que, de fato, há mudanças constantes nestes parâmetros, principalmente devido às adequações cada vez maiores dos produtores ao mercado consumidor à maior importância dada ao mercado de produtos processados.

$\mathrm{O}$ rendimento de carcaça foi diferente entre as linhagens apenas quando as aves foram abatidas com 35 dias de idade, porém, não houve diferenças nas idades de 42 e 49 dias. Huyghebaert et al. (1991) avaliaram o efeito do genótipo de duas linhagens (magra vs comercial) sobre parâmetros de rendimento de carcaça e partes para abate com 45 e 56 dias, observaram que as características de carcaça foram pouco afetadas pela linhagem. Mendes et al. (1993) também não observaram diferenças para o rendimento de carcaça ao avaliarem as linhagens Arbor Acres e Hubbard, aos 42 dias, porém verificaram diferenças para rendimento de pernas entre as linhagens. No entanto, Souza et al. (1994) encontraram diferenças para o rendimento de carcaça, pernas e peito entre as linhagens Arbor Acres, Hubbard, Cobb e Ross aos 42 dias. Lisboa et al. (1999a), avaliando o rendimento de carcaça de três grupos genéticos de frangos de corte obtidos na Universidade Federal de Viçosa, verificaram diferenças entre os genótipos para rendimento de carcaça, peito e coxa. Os machos apresentaram maiores rendimento de coxa e sobre coxa e menores rendimen- tos de peito e gordura abdominal do que as fêmeas, aos 42 dias de idade. Vieira \& Moran (1998), avaliando o rendimento de carcaça de quatro diferentes linhagens de frangos de corte aos 49 dias, também não encontraram diferenças para o rendimento de carcaça, porém, verificaram diferenças de até $20 \%$ na quantidade de gordura abdominal entre diferentes linhagens comerciais. Os depósitos de gordura são ainda em maior proporção em fêmeas do que em machos e isto é causado principalmente pela existência de adipócitos de maior tamanho nas fêmeas. As fêmeas produzem carcaças com 2,5\% mais de gordura do que machos (Langslow \& Lewis, 1974). Diferenças para gordura abdominal entre linhagens também foram verificadas por Farran et al. (2000), porém, Souza et al. (1994) e Fernandes et al. (2001) não encontraram diferenças nesta característica.

$\mathrm{O}$ rendimento de peito e carne de peito foi diferente entre as linhagens nas três idades avaliadas, o que corrobora os achados de Souza et al. (1994), Smith et al. (1998), Lisboa et al. (1999) e Moreira et al. (2001), que também observaram diferenças neste parâmetro, ao estudarem diferentes linhagens. Porém, Mendes et al. (1993), não observaram efeito das linhagens para carne do peito, mas verificaram influência sobre o rendimento de carne de pernas. Le BihanDuval et al. (1999), comparando uma linhagem de frangos de corte selecionada por 13 gerações, para aumento de peso corporal e rendimento de carne de peito em relação a uma linhagem controle que não 
sofreu seleção, verificaram diferenças para peso corporal, rendimento de carne de peito e gordura abdominal, sendo que a linhagem selecionada foi superior para peso corporal e rendimento de carne de peito e teve menor teor de gordura abdominal. Estes dados comprovam que a seleção das linhagens para alto rendimento de fato promove maior rendimento de peito e carne de peito nas aves, o que foi constatado neste trabalho, evidenciando que as linhagens de conformação apresentaram rendimentos semelhantes ou superiores ao das linhagens convencionais, e que portanto isto se deve a um aperfeiçoado processo de seleção genética entre as linhagens.

Moreira et al. (2001), avaliando parâmetros físicos e de qualidade da carne do peito em três diferentes linhagens de conformação aos 42 dias, também verificaram diferenças entre as linhagens para peso, espessura, largura e perda de peso por cozimento dos filés mas, não observaram diferenças na força de cizalhamento e no $\mathrm{pH}$ do peito. Estes resultados, à exceção dos resultados de perda de peso por cozimento, são semelhantes aos deste trabalho, indicando que as linhagens comerciais atuais são mais específicas nestas características. Berri et al. (2001), comparando parâmetros de qualidade da carne e características do músculo de quatro linhagens de frangos de corte, uma linha experimental, uma linha selecionada para alto rendimento de peso corporal e peito e linhas não selecionadas, observaram que ambas linhas selecionadas apresentaram menor queda e extensão do declínio do $\mathrm{pH}$ postmortem, porém, isto não refletiu na qualidade final da carne. Diferenças no $\mathrm{pH}$ da carne em frangos de diferentes linhagens também foram observadas por Qiao et al. (2001), porém, neste estudo, estes dados não foram confirmados. Le Bihan-Duval et al. (2001), avaliando parâmetros de qualidade da carne de frangos de corte, confirmaram a hipótese de que a seleção de frangos para rápido crescimento não tem efeitos sobre a qualidade da carne de peito. Poole et al. (1999), avaliando o efeito da linhagem e idade sobre o rendimento de filés cozidos de peito de frangos e maciez com 5, 6, 7 e 8 semanas, não verificaram efeito das linhagens sobre maciez. Porém, a idade teve influência sobre os valores de força de cizalhamento que foram de 2,73 a $4,17 \mathrm{~kg}$ da $5^{\mathrm{a}}$ à $8^{\mathrm{a}}$ semana. Os dados de qualidade da carne encontrados neste trabalho também não revelaram diferenças pelo fato da seleção aplicada nas linhagens, reforçando, portanto, os dados da literatura mencionados.

\section{Conclusões}

O desempenho de frangos de corte é diferente tanto entre as linhagens convencionais quanto entre as linhagens de conformação, sendo que há entre as linhagens convencionais linhagens com melhor desempenho do que algumas de conformação e viceversa. Com relação ao rendimento de carcaça, peito e carne de peito, as linhagens de conformação apresentam superioridade em relação as linhagens convencionais, apesar de apresentarem pior rendimento de pernas e de carne de pernas. A percentagem de gordura abdominal não foi influenciada pelas diferenças entre as linhagens. Há diferenças quanto ao rendimento de filés do peito entre as linhagens, refletindo as diferenças sobre o rendimento da carne do peito, com as linhagens de conformação apresentando os maiores valores. Não há efeito das linhagens sobre os parâmetros de qualidade da carne. O sexo das aves teve influência tanto no desempenho quanto no rendimento de carcaça e partes, mas não influenciou a qualidade da carne.

Portanto, para o comércio de aves vivas ou carcaças inteiras, há linhagens tanto de conformação quanto convencionais que apresentam resultados semelhantes, porém, para mercados mais específicos, como o de partes e produtos processados, as linhagens de conformação apresentam maior rentabilidade, uma vez que apresentam maiores rendimentos principalmente de carne de peito, sem prejuízos à qualidade da carne.

\section{Literatura Citada}

ABREU, V.M.N.; SILVA, M.A.; TORRES, R.A. et al. Características produtivas de linhagens de corte. Revista Brasileira de Zootecnia, v.25, n.1, p.83-91, 1996.

ARAÚJO, L.F.; JUNQUEIRA, O.M.; ARAÚJO, C.S.S. et al. Diferentes níveis de lisina para duas linhagens de frangos de corte na fase final de criação. In: CONFERENCIA APINCO DE CIENCIA E TECNOLOGIA AVICOLAS, 1999. Suplemento da Revista Brasileira de Ciência Avícolas, n.1, p.43.

BAKKER, W. Manejo dos machos reprodutores. In: ANAIS DA CONFERÊNCIA APINCO DE CIÊNCIA E TECNOLOGIA AVÍCOLAS, 1999, Campinas. Anais... Campinas: FACTA, 1999. v.2, p.84-96.

BERAQUET, N. Influência de fatores ante e post mortem na qualidade da carne de aves. Revista Brasileira de Ciência Avícolas, n.1, p.155-166, 1999.

BERRI, C.; WACRENIER, N.; MILLET, N. et al. Effect of selection for improved body composition on muscle and meat characteristics of broilers from experimental and commercial lines. Poultry Science, n.80, p.833-838, 2001.

CASTILLO, C.J.C. Qualidade de carcaça e carne de aves. In: 
CONGRESSO BRASILEIRO DE CIÊNCIA E TECNOLOGIA DE CARNES, 1., 2001, São Pedro. Anais... São Pedro: ITAL, 2001. p.79-99.

FARRAN, M.T.; KHALIL, R.F.; UWAYJAN, M.G. et al. Performance and carcass quality of commercial broiler strain. Journal of Applied Poultry Research, v.9, n.2, p.252-257, 2000.

FERNANDES, L.M.; VIEIRA, S.L.; KINDLEIN, G. et al. Avaliação do crescimento e rendimento de carcaça de linhagens comerciais e dois tipos de bebedouro. In: CONFERENCIA APINCO DE CIENCIA E TECNOLOGIA AVICOLAS, 2001. Suplemento da Revista Brasileira de Ciência Avícolas, n.3, p.1.

FRONING, G.W.; BABJI, A.S.; MATHER, F.B. The effect of preslaughter temperatures, stress, atruggle and anesthetization on color and textural characteristics of turkey muscle. Poultry Science, v.57, n.3, p.630-633, 1978.

HONIKEL, K.O. The water binding of meat. Fleischwirttssch, v.67, p.1098-1102, 1987.

HUYGHEBAERT, G.; DEMUNTER, G.; DEGROOTE, G. et al. The effects of dietary factors and genotype on performances and carcass quality of broiler-chickens. Landbouwtijdschrift Revista Del Agriculture, v.44, n.2, p.221-236, 1991.

LANGSLOW, D.R.; LEWIS, R.J. Alterations with age in composition and lipolytic activity of adipose tissue from male and female chickens. British Poultry Science, n.15, p.267-273, 1974

LE BIHAN-DUVAL, E.; MILLET, N.; REMIGNON, H. Broiler meat quality: Effect of selection for increased carcass quality and estimates of genetic parameters. Poultry Science, n.78, p.822-826, 1999.

LISBOA, J.S.; SILVA, D.J.; SILVA, M.A. et al. Rendimento de carcaça de três grupos genéticos de frangos de corte alimentados com rações contendo diferentes teores de proteína. Revista Brasileira de Zootecnia, v.28, n.3, p.548-554, 1999a.

LISBOA, J.S.; SILVA, D.J.; SILVA, M.A. et al. Desempenho de três grupos genéticos de frangos de corte alimentados com rações contendo diferentes teores de proteína. Revista Brasileira de Zootecnia, v.28, n.3, p.555-559, 1999 b.

LUBRITZ, S.L. A statistical model for white meat yield in broiler. Journal of Applied Poultry Research, n.6, p.253-59, 1997.

MACK, S.; PACK, M. Desenvolvimento de carcaças de frangos: influência dos aminoácidos da dieta. In: CONFERENCIA APINCO DE CIENCIA E TECNOLOGIA AVICOLAS, 2000, Campinas. Anais... Campinas: APINCO, 2000. p.145-160.

MENDES, A.A.; GARCIA, E.A.; GONZALES, E. et al. Efeito da linhagem e idade de abate sobre o rendimento de carcaça de frangos de corte. Revista Brasileira de Zootecnia, v.22, n.3, p.466-472, 1993.

MENDES, A.A. Rendimento e qualidade da carcaça de frangos de corte. In: CONFERENCIA APINCO DE CIENCIA E TECNOlOGIA AVICOLAS, 2001, Campinas. Anais... Campinas: APINCO, 2001. p.79-99.

MIZUBUTI, I.Y.; FONSECA, N.A.N.; PINHEIRO, J.W. Desempenho de duas linhagens comerciais de frango de corte, criadas sob diferentes densidades populacionais e diferentes tipos de cama. Revista Brasileira de Zootecnia, v.23, n.3, p.476-484, 1994.

MOREIRA, J.; MENDES, A.A.; GARCIA, R.G. et al. Avaliação do rendimento e qualidade da carne em frangos de corte de diferentes linhagens e densidades. In: CONGRESSO BRASILEIRO DE CIÊNCIA E TECNOLOGIA DE CARNES, 1. 2001, São Pedro. Anais... São Pedro: ITAL, 2001. p.205-206.

NOBRE, R.T.R.; SILVA, D.J.; TAFURI, M.L. et al. Efeito do nível de energia sobre o desempenho de diferentes grupos genéticos de frangos de corte. Revista Brasileira de Zootecnia, v.23, n.4, p.595-602, 1994.

POOLE, G.H.; LYON, C.E.; BUHR, J.R. et al. Evaluation of age, gender, strain, and diet on the cooked yield and shear values of broiler breast fillets. Journal of Applied Poultry Research, n.8, p.170-176, 1999.

QIAO, M.; FLETCHER, D.L.; SMITH, D.P. et al. The effect of broiler meat color on $\mathrm{pH}$, moisture, water-holding capacity, and emulsification capacity. Poultry Science, n.80, p.676680, 2001.

ROSTAGNO, H.S.; ALBINO, L.F.T.; DONZELE, J.L. et al. Tabelas brasileiras para aves e suínos: composição de alimentos e exigências nutricionais. Viçosa, MG: Universidade Federal de Viçosa, 2000. 141p.

SAS INSTITUTE, SAS user's guide. Cary: 1996.

SMITH, E.R.; PESTI, G.M.; BAKALLI, R.I. et al. Further studies on the influence of genotype and dietary protein on the performance of briolers. Poultry Science, v.77, n.11, p.1678-1687, 1998.

SOUZA, P.A.; SOUZA, H.B.A.; CAMPOS, F.P. et al. Desempenho e características de carcaça de diferentes linhagens comerciais de frangos de corte. Revista Brasileira de Zootecnia, v.23, n.5, p.783-791, 1994.

VIEIRA, S.L.; MORAN, J.R. et al. Broiler yields using chicks from egg weight extremes and diverse strains. Journal of Applied Poultry Research, n.7, p.339-346, 1998. 